\title{
Percepciones de la población costarricense sobre el referéndum y la implementación del TLC a diez años de su aprobación*
}

Recibido: 13 de marzo 2018

Revisado: 29 de junio 2018

Aprobado: 24 de julio 2018

José Andrés Díaz González

Egresado del Doctorado en Gobierno y Políticas Públicas de la Universidad de Costa Rica (UCR). Licenciado en Ciencias Políticas (UCR) y Mágister en Historia. Investigador en el Programa Umbral Político del Instituto de Estudios Sociales en Población (IDESPO) de la Universidad Nacional de Costa Rica (UNA) y docente de la Escuela de Ciencias Políticas de la UCR. Correo electrónico: jose.diaz.gonzalez@una.cr

Sindy Mora Solano Estudiante del Doctorado en Sociedad y Cultura de la Universidad de Costa Rica. Licenciada en Sociología (UCR) y Máster en Derechos Humanos y Educación para la Paz (UNA). Investigadora en el Programa Umbral Político del Instituto de Estudios Sociales en Población (IDESPO) de la Universidad Nacional de Costa Rica (UNA) y docente en la Escuela de Estudios

Generales de la UCR.

Correo electrónico: sindy.mora.solano@una.cr
Resumen: En el año 2007, se realizó el referendo sobre el TLC en Costa Rica. Ha sido una de las coyunturas sociales y políticas más conflictivas de la historia costarricense reciente. Debido a esto, se analizó la percepción de la población costarricense sobre este tratado, tras diez años de su aprobación. Entre los principales resultados, se encuentra que es un tema que aún polariza la opinión pública costarricense; asimismo, el criterio mayoritario de la población es que este tratado comercial ha beneficiado a grandes empresarios nacionales y extranjeros, y ha tenido poco o ningún beneficio para los consumidores y pequeños empresarios. Además, la población percibe que la discusión académica fue la que tuvo mayor influencia a la hora de decidir su voto.

Palabras clave: Costa Rica; CAFTA; referendo; opinión pública; comercio

\section{Perceptions of the Costa Rican Population about the Referendum} and the Implementation of the CAFTA Ten years after its Approval

Abstract: In 2007, the referendum on the CAFTA-DR was carried out in Costa Rica. This has been one of the most conflictive social and political conjunctures in recent Costa Rican history. Due to this, the perception of the Costa Rican population about this treaty is analyzed after ten years of its approval. Among the main results it is observed that the CAFTA-DR is a subject that still polarizes the Costa Rican public opinion; likewise, the majority criterion of the population is that this commercial treaty has benefited large national and foreign entrepreneurs, and has had little or no benefit for consumers and small entrepreneurs. In addition, the population perceives that it was the academic discussion that had the most influence at the time of deciding their vote.

Key words: Costa Rica; CAFTA; Referendum; public opinion; commerce 
Los que hoy vienen en bicicleta, con el TLC vendrán en motocicleta BMW, y los que vienen en un Hyundai, vendrán en un Mercedes Benz, en esto consiste el desarrollo

Óscar Arias Sánchez

Presidente de Costa Rica, 2006-2010

Frase que se le atribuye durante la campaña del referendo del TLC, 2007

\begin{abstract}
* Este artículo se publica un año después de realizada la Encuesta A Diez Años del referendo del TLC: Percepciones sobre sus implicaciones sociales, económicas y políticas, 2017. La investigación se llevó a cabo en el marco del proyecto de investigación "Contextos sociopolíticos emergentes y su relación con la cultura política en Costa Rica", del Programa Umbral Político del Instituto de Estudios Sociales en Población (IDESPO) de la Universidad Nacional de Costa Rica (UNA). Se agradece el trabajo del equipo de supervisión y aplicación de encuestas del Centro Tecnológico de Investigación Social (CETIS) por su labor en el proceso de recolección de datos para la elaboración del presente artículo.
\end{abstract}

Posiblemente, la discusión en relación con el Tratado de Libre Comercio entre Centroamérica, República Dominicana y Estados Unidos (CAFTA-DR por sus siglas en inglés, conocido de manera coloquial como TLC) y el referendo celebrado en el año 2007, que permitió su aprobación, constituye uno de los periodos de mayor conflictividad social y política en la historia reciente de Costa Rica. Dado esto, no es de extrañar que este fenómeno haya sido objeto de una gran cantidad de análisis académicos, los cuales han abordado desde los aspectos y las repercusiones comerciales y políticas del TLC (Pinder 2009; Behlman 2014; Taylor, Naude, y Jesurun-Clements 2010), el referendo como mecanismo de toma de decisiones (Cortés Ramos 2008; Raventós Vorst 2008; Alfaro Redondo 2006; Alfaro Salas y Díaz González 2008; Alfaro Redondo 2009; Urbatsch 2013), hasta la participación de la ciudadanía, grupos de la sociedad civil, empresarios y partidos políticos en este proceso (Finley-Brook y Hoyt 2009; Frajman 2012; Spalding 2007; Willis y Seiz 2012; Álvarez Rudín 2011; Cupples y Larios 2010; Mora Solano 2009; Rojas Bolaños 2009).

De acuerdo con esta manera, dadas las implicaciones y repercusiones que ha tenido para la sociedad costarricense, tanto el TLC como el referendo por el cual se aprobó, resulta necesario analizar cuál es la percepción de la población costarricense sobre el impacto que ha tenido este tratado comercial, tras diez años de su aprobación. Así, este artículo inicia presentado brevemente la coyuntura social y política que se vivió en Costa Rica durante el proceso de aprobación del TLC, con el propósito de comprender el contexto en el cuál la ciudadanía costarricense tuvo que acudir al referendo para elegir si aprobaba o rechazaba este Tratado. En un segundo momento, se analiza cuáles son las percepciones de la población sobre el TLC y el referendo, tras una década de su realización. Para ello, se recurre a datos de un estudio de opinión pública, el cual se realizó específicamente con dicho propósito. Por último, se exponen las principales conclusiones del estudio. 


\section{Coyuntura social y política en tiempos del referendo sobre el TLC}

La coyuntura de discusión y de aprobación del TLC ha sido una de las más conflictivas de la historia reciente del país. En el contexto del proceso electoral del año 2006, catalogado por Rojas Bolaños $(2009,18)$ como un proceso en donde "la propaganda sustituyó el debate", las implicaciones del TLC no fueron discutidas. Si bien el candidato presidencial del Partido Liberación Nacional (PLN) y uno de sus principales promotores, Óscar Arias Sánchez, no ocultó su apoyo al Tratado en caso de que llegara a la presidencia de la República. Durante todo el proceso electoral, Arias evitó hacer extensivas declaraciones respecto al TLC.

Con el triunfo liberacionista en las elecciones del año 2006, el tratado comercial se aprobó en la segunda administración Arias Sánchez (2006-2010). Así su llegada al poder fue un movimiento estratégico para posicionar el proceso de liberalización económica y la agenda de apertura comercial (Rojas Bolaños 2009). Las administraciones predecesoras, en particular, las correspondientes a los gobiernos socialcristianos de Miguel Ángel Rodríguez Echeverría (1998-2002) y Abel Pacheco de la Espriella (2002-2006) no habían logrado consolidar los proyectos político-económicos de los grupos de poder costarricense; por lo tanto, la administración Arias Sánchez tenía como objetivo fundamental la aprobación del tratado comercial. De esta manera, la segunda llegada de Arias a casa presidencial fue un eslabón en el proceso de concreción de un proyecto económico que había tenido diversos obstáculos y que se encontraba pendiente (Mora Solano 2016).

En este escenario, distintos actores políticos, entre los que destacaban sectores de pequeños y medianos productores, organizaciones de carácter sindical, ambientalistas, estudiantiles, mujeres, indígenas y empresarios, se fueron aglutinando en el marco de distintas expresiones organizativas, que acumulaban malestares más allá de la posible aprobación del TLC. De esta forma, durante el proceso de discusión y de organización en contra del Tratado, en el proceder de estos actores, se mantuvieron vigentes una serie de tensiones políticas. Se destacaron las siguientes: la modificación del artículo 132 de la Constitución Política, que permitió la reelección presidencial de Arias Sánchez, así como las denuncias de fraude electoral en el marco de las elecciones del año 2006, planteadas ante el Tribunal Supremo de Elecciones (TSE) (Rojas Bolaños 2009; Mora Solano 2016).

A estos malestares se sumaron las dificultades propias del primer referendo celebrado en el país, vinculadas a la reglamentación del instrumento político aplicado, al financiamiento de ambas posiciones, a la participación política del presidente de la República, diputados y diputadas y funcionarios públicos a favor del TLC y en relación con el acceso a los medios de comunicación (Cortés Ramos 2008; Álvarez Rudín 2011). Dichas molestias tomaron formas diversas. Como señala Almeida, el movimiento del TLC se conformó como una campaña de protesta, es decir, como una manera organizativa a corto plazo, en la que los recursos disponibles se articularon en la oposición al Tra- 
1. Según los datos de la Encuesta Nacional de Hogares (2014) del Instituto Nacional de Estadística y Censos (INEC), esto abarca aproximadamente al $53,8 \%$ de las personas mayores de 18 años; lo cual implica que toda generalización que se haga con base en estos datos debe referirse estrictamente a la población costarricense con teléfono residencial y no la población costarricense en su totalidad. tado comercial (Almeida 2016). El surgimiento de los comités patrióticos fue una de las características particulares de este proceso (Raventós Vorst 2008; Álvarez Rudín 2011).

Valga señalar que, una vez aprobado el TLC en el referendo, debía aprobarse la llamada "agenda de implementación", lo que se realizó no sin oposición de distintos actores políticos (Mora Solano 2016). Diez años después del referendo por el TLC, quisimos conocer las percepciones de la población respecto a un tratado comercial que, sin duda, dejó importantes huellas en la cultura política del país.

\section{Aspectos metodológicos}

Para conocer la percepción de la población costarricense sobre las repercusiones del TLC a diez años del referendo, así como la utilidad de los referendos como instrumentos para la toma de decisiones, se aplicó la encuesta "A Diez Años del referendo del TLC: Percepciones sobre sus implicaciones sociales, económicas y políticas". La encuesta se realizó vía telefónica a hogares, a nivel nacional, que cuentan con servicio de telefónico era proporcionado por el Instituto Costarricense de Electricidad (ICE), ${ }^{1}$ y se aplicó del 22 de mayo al 2 de junio del 2017. Para ello, se calculó una muestra de 600 personas, costarricenses, de 28 años o más. La muestra se constituyó a partir de cuotas de sexo y edad, con el propósito de que fuera lo más representativa posible de la población costarricense con dichas características. Los resultados cuentan con un nivel de confianza de 95\% y un margen de error de \pm 4\%. La información recolectada, así como todos los cálculos y análisis estadísticos presentados en este artículo, se procesó utilizando el software Statistical Package for Social Science (SPSS).

A diferencia de las encuestas habitualmente realizadas por el IDESPO; en este caso, la muestra se construyó con personas mayores de 28 años para garantizar que las personas entrevistadas tuvieran 18 años o más en el 2007, pues en este año se realizó el referendo sobre el TLC. En otras palabras, la población de estudio consiste en personas que tenían pleno ejercicio de sus derechos ciudadanos y estaban habilitadas para votar en el referendo.

Cuadro 1. Porcentaje de personas entrevistadas según sexo, 2017

\begin{tabular}{lcc}
\hline & Sexo & Porcentaje \\
\hline Femenino & $54,3 \%$ \\
Masculino & $45,6 \%$ \\
Total & $100 \%$ \\
\hline
\end{tabular}

IDESPO-UNA. Encuesta A Diez Años del referendo del TLC: Percepciones sobre sus implicaciones sociales, económicas y políticas, 2017. 
Como ya se indicó, la muestra se construyó tomando en consideración cuotas de sexo y edad, para garantizar que los resultados obtenidos fueran lo más representativos posibles de las percepciones de la población costarricense mayor a 28 años. Así, 52,13\% de la población entrevistada fue de sexo femenino; y 47,88\%, de sexo masculino (ver cuadro 1). En el caso de la distribución de la población por grupos de edad, se realizó el control de las cuotas, para garantizar una distribución proporcional a la población de cada grupo etario (ver cuadro 2).

Cuadro 2. Porcentaje de personas entrevistadas según grupo etario, 2017

\begin{tabular}{cc}
\hline Grupo etario & Porcentaje Válido \\
\hline 28 a 32 & 9,3 \\
33 a 37 & 9,0 \\
38 a 42 & 9,50 \\
43 a 47 & 9,50 \\
48 a 52 & 11,50 \\
53 y más & 51,2 \\
Total & $\mathbf{1 0 0 \%}$ \\
\hline
\end{tabular}

IDESPO-UNA. Encuesta A Diez Años del referendo del TLC: Percepciones sobre sus implicaciones sociales, económicas y políticas, 2017.

Respecto al nivel de escolaridad, es necesario señalar que $42,8 \%$ indica tener estudios universitarios completos o posgrado universitario, mientras que $56,8 \%$ no cuenta con educación universitaria. De esta manera, se aprecia que la población costarricense consultada se concentra en dos grandes grupos: el primero, de bajo nivel de escolaridad; y el segundo, de un alto nivel de escolaridad.

\section{Cuadro 3. Porcentaje de personas entrevistadas según nivel de escolaridad,} 2017

\begin{tabular}{lc}
\hline \multicolumn{1}{c}{ Nivel de escolaridad } & Porcentaje \\
\hline Ninguna & 0,5 \\
Primaria incompleta & 6,9 \\
Primaria completa & 17,0 \\
Secundaria incompleta & 12,4 \\
Secundaria completa & 13,2 \\
Universitaria incompleta & 1,2 \\
Para universitaria completa & 6,1 \\
Universitaria completa (Bachiller o licenciatura) & 34,4 \\
Posgrado universitario completo & 8,4 \\
(Doctorado/maestría) & $\mathbf{1 0 0 \%}$ \\
Total &
\end{tabular}

IDESPO-UNA. Encuesta A Diez Años del referendo del TLC: Percepciones sobre sus implicaciones sociales, económicas y políticas, 2017. 
Los datos arrojados por la encuesta señalada fueron analizados utilizando estadística descriptiva e inferencial. En cuanto al análisis estadístico inferencial, se realiza un análisis factorial exploratorio, el cual es una técnica multivariada, cuyo principal objetivo es describir una serie de datos con muchas variables mediante un número menor de variables denominadas factores (Pignataro 2016, 86). Así, este análisis se aplica para reducir las variables que pueden haber influido en la decisión del voto de la población en el referendo sobre el TLC (cuadro 11). Tomando en cuenta esos factores, así como otras variables sociodemográficas, se construyó un modelo de regresión logística binaria para establecer cómo estos elementos inciden en la probabilidad de la población encuestada de haber votado sí o no por el TLC.

\section{Antecedente: Opinión de la población antes del referendo}

En marzo del 2007, el IDESPO realizó un estudio de opinión pública, en el cual se le consultó a la población costarricense diversos aspectos relacionados con el TLC (IDESPO-UNA 2007). En ese momento, aún no se había convocado la realización del referendo para que las ciudadanas y los ciudadanos decidieran sobre este tema; sin embargo, ya desde el año 2006, algunos grupos que se oponían al TLC habían venido posicionando en la esfera pública la idea de utilizar este mecanismo de consulta popular (Rojas Bolaños 2009).

Así, se consultó a la población encuestada sobre cuál consideraban que sería la principal ventaja que traería el TLC para el país en caso de ser aprobado (ver cuadro 4). El segmento mayoritario, casi 41\%, contestó que este generaría más empleos al país. Es necesario indicar que, desde los promotores del Tratado, incluyendo a las autoridades del Gobierno, así como los entes privados creados para promover la aprobación del TLC, el tema de la generación de empleo era el principal argumento esgrimido para defenderlo (Willis y Seiz 2012).

Sin embargo, llama la atención que la identificación de que el TLC "no traerá ningún beneficio para el país" ocupó el segundo lugar, siendo mencionado casi por $16 \%$ de la población encuestada. En tercer lugar, casi 9\% indicó que no sabía o no podía responder a la pregunta. El resto de las ventajas mencionadas que podría traer el TLC fueron nombradas por menos de $7 \%$ de las personas entrevistadas. Estos datos permiten inferir que, si bien $40 \%$ de la población visualizaba como principal ventaja la base de la campaña de los grupos promotores del Tratado, el resto de la población no visualizaba una ventaja clara, o bien, consideraba que no traería ninguna ventaja al país. 
Cuadro 4. Principal ventaja del TLC identificada por la ciudadanía costarricense, marzo, 2007

\begin{tabular}{lc}
\hline \multicolumn{1}{c}{ Ventaja } & $\begin{array}{c}\text { Porcentaje } \\
(\boldsymbol{n}=600)\end{array}$ \\
\hline Más empleos & 40,8 \\
No traerá ninguna ventaja & 15,9 \\
No sabe/No Responde & 8,7 \\
Mayor Exportación & 6,9 \\
Eliminación de Monopolios & 5,4 \\
Mejores y diversos productos & 5,2 \\
Más competitividad & 4,5 \\
Permitirá salir a Costa Rica del subdesarrollo & 3,3 \\
Mayor inversión extranjera & 1,6 \\
Es beneficioso para Costa Rica & 1,5 \\
Productos más baratos & 1,1 \\
Habrá más empresas & 1,1 \\
No está informado & 0,5 \\
Otro & 2,8 \\
Total & $\mathbf{1 0 0 \%}$ \\
\hline
\end{tabular}

IDESPO-UNA. Encuesta Percepción de la Población costarricense sobre Asamblea Legislativa y gobierno. Marzo, 2007

Una situación similar se presenta al revisar las respuestas dadas por la muestra encuestada respecto de la principal desventaja que traería el TLC para el país (ver cuadro 5). En este caso, el segmento mayoritario, casi $26 \%$, indicó que traería un impacto negativo a la economía nacional; mientras que el segundo grupo, cerca de $15 \%$, se compuso de las personas que indicaron no saber o no poder responder a las preguntas. En tercer y cuarto lugar, con porcentajes similares, se encuentran quienes indicaron como desventajas la privatización de instituciones públicas y el aumento de los problemas sociales. En este caso, menos de 7\% indicó que el TLC no traería desventajas al país.

Estos datos constatan que, a inicios de 2007, no había un criterio uniforme entre la población costarricense acerca de los efectos positivos y negativos que podría traer el TLC al país. Esta situación no es de extrañar, ya que el Tratado comercial que se discutía incluía temas muy complejos y diversos, desde la protección de obtenciones vegetales hasta la ruptura de los monopolios públicos en telecomunicaciones y seguros. 
Cuadro 5. Principal desventaja del TLC identificada por la ciudadanía costarricense, marzo 2007

\begin{tabular}{lc}
\hline \multicolumn{1}{c}{ Desventaja } & $\begin{array}{c}\text { Porcentaje } \\
(\boldsymbol{n}=\mathbf{6 0 0})\end{array}$ \\
\hline Impacto negativo en la economía nacional & 25,6 \\
No sabe-No responde & 15,0 \\
Privatización de instituciones públicas & 8,9 \\
Aumento de los problemas sociales (desempleo, & 8,5 \\
pobreza, etc,) & 6,5 \\
Ninguna desventaja & 5,0 \\
EE. UU, se aprovechará de Costa Rica & 4,7 \\
Pérdida de autonomía del país & 4,6 \\
Debilitamiento del Estado costarricense & 3,5 \\
Destrucción del ambiente & 2,5 \\
Favorecimiento a grandes empresas & 1,8 \\
Extranjeros ocuparán el trabajo de los costarricenses & 1,5 \\
Aumento del precio de productos básicos & 1,5 \\
Pagar más impuestos & 1,1 \\
Saturación de productos & 1,1 \\
Competencia desleal & 1,0 \\
Pérdida de la identidad costarricense & 0,7 \\
El Tratado no fue adecuadamente negociado & 0,5 \\
No está informado & 5,0 \\
Otro & $\mathbf{1 0 0 \%}$ \\
Total & \\
DESPO-UNA. Encuesta Percepción de la Población costarricense sobre Asamblea Legislativa \\
y gobierno. Marzo, 2007
\end{tabular}

En el marco de la situación anterior, ya se empezaba a observar una polarización de la población respecto al TLC. En el año 2007, 30\% de la población se manifestaba contra el TLC, mientas que casi $40 \%$ indicaba algún tipo de posición favorable hacia este. Un elemento adicional por destacar es que, casi 30\% indicó estar indeciso sobre el Tratado (ver cuadro 6).

Finalmente, los resultados del referendo del 7 de octubre dieron la victoria al Sí, con 52\% de los votos, mientras que el No obtuvo 48\%. Asimismo, el abstencionismo fue de $40 \%$ del padrón electoral. Sobre este último dato, si bien el porcentaje de personas que se abstuvo de asistir a las urnas en el referendo no es muy distinto a la tendencia que se ha presentado en el país en las elecciones nacionales, desde el 2002, ha sido sujeto a diversas interpretaciones. 
Cuadro 6. Posición de la población costarricense ante el TLC,

\begin{tabular}{lc}
\multicolumn{2}{c}{ marzo 2007 } \\
\hline \multicolumn{1}{c}{ Posición ante el TLC } & $\begin{array}{c}\text { Porcentaje } \\
(\boldsymbol{n}=\mathbf{6 0 0})\end{array}$ \\
\hline Totalmente a favor & 16,2 \\
Más a favor que en contra & 23,3 \\
Indeciso & 26,1 \\
Indiferente & 1,3 \\
Más en contra que a favor & 13,7 \\
Totalmente en contra & 16,5 \\
Lo desconoce & 2,2 \\
No sabe-No responde & 0,5 \\
Total & $\mathbf{1 0 0}$ \\
\hline
\end{tabular}

IDESPO-UNA. Encuesta Percepción de la Población costarricense sobre Asamblea Legislativa y gobierno. Marzo, 2007

Por un lado, encontramos los trabajos que señalan que es parte de la postura que la población costarricense ha adoptado respecto a la política, especialmente hacia los procesos electorales, por el descontento y la decepción de la población respecto de los partidos políticos, tanto por diversos escándalos de corrupción que han envuelto a altas figuras de la política costarricense, incluyendo expresidentes, así como por una incapacidad efectiva de estas agrupaciones de dar respuesta a las problemáticas nacionales una vez que llegan a las instancias de Gobierno (Alfaro Redondo 2009; Raventós Vorst et al. 2014; Rojas Bolaños 2009). Por otra parte, encontramos los análisis académicos que, si bien no niegan la existencia de un proceso de desafección política en la población costarricense e incluso una erosión hacia su apoyo a la democracia; encuentran que los temas que cubría el TLC y la legislación conexa que requería (llamada popularmente como "Agenda de Implementación") eran muy diversos y complejos para el desarrollo de una adecuada discusión pública, con el propósito de que la ciudadanía pudiera generar un criterio para la toma de una decisión acertada. Estos trabajos concluyen no solamente que el abstencionismo puede deberse, al menos en parte, a la imposibilidad de la población de procesar la información y tomar una decisión; sino que, también, las personas que fueron a votar tanto por el "Sí" o por el "No", no necesariamente comprendían de manera completa todas las implicaciones de su posición. Debido a esta situación, y sumado a otras carencias encontradas en el proceso del referendo, los estudios concluyen que, finalmente, generó un impacto negativo en la democracia costarricense (Rayner 2014; Willis y Seiz 2012).

A la tesis anterior se le puede sumar la existencia de fuertes críticas, que se dieron en el momento, respecto al acceso de recursos por las campañas del "Sí" y del "No", así como de la supuesta parcialidad de diversas instituciones públicas, incluso el propio Tribunal Supremo de Elecciones. Diversos autores 
y autoras han señalado que estos últimos elementos interfirieron en los resultados de la consulta popular (Alfaro Salas y Díaz González 2008; Álvarez Rudín 2011; Mora Solano 2016; Cortés Ramos 2008; Raventós Vorst 2008). Si bien no se puede indicar con precisión si afectaron el resultado, así como en qué grado lo hicieron, sí se ha podido constatar -como se profundizará más adelante- que a diez años del referendo estas críticas al proceso aún siguen vigentes en la opinión pública costarricense.

\section{Percepción de la población costarricense a diez años del TLC}

A las personas que participaron en la encuesta "A Diez Años del referendo del TLC: Percepciones sobre sus implicaciones sociales, económicas y políticas", se les consultó si habían acudido a votar en el referendo sobre el TLC en el 2007. El 52,4\% indicó que sí acudió a emitir su voto y 43,4\% manifestó que no fue a votar. Estos datos son muy similares a los resultados electorales obtenidos en el referendo, ya que en este, 59,2\% acudió a las urnas y 40,8\% se abstuvo de emitir su voto. La diferencia entre los datos obtenidos en la encuesta con los resultados del referendo sobre el TLC, tanto para este como para otros datos que se expondrán más adelante, se debe a que la encuesta se realizó a teléfonos fijos en casas de habitación, lo cual cubre menos de $50 \%$ de la población costarricense. Sin embargo, los resultados son lo suficientemente similares para suponer que no hay una pérdida significativa de representatividad de los resultados de la encuesta respecto del total de la población en estudio.

Cuadro 7. Porcentaje de personas según si fueron o no a votar en el referendo sobre el TLC, 2017

\begin{tabular}{lc}
\hline \multicolumn{1}{c}{ Fue a votar } & $\begin{array}{c}\text { Porcentaje } \\
(\mathbf{n}=\mathbf{6 0 0})\end{array}$ \\
\hline Sí & 52,4 \\
No & 43,4 \\
Ns/Nr & 4,2 \\
Total & 100 \\
\hline
\end{tabular}

IDESPO-UNA. Encuesta A Diez Años del referendo del TLC: Percepciones sobre sus implicaciones sociales, económicas y políticas, 2017.

A las personas que asistieron a votar se les consultó por cuál opción emitió su voto: 49,7\% indicó que votó por el Sí"; y 42,8\%, por el No. Estos datos difieren levemente con los resultados obtenidos en el referendo, en el cual $52 \%$ votó por el Sí; mientras que 48\%, por el No. Sin embargo, si tomamos en consideración el margen de error de la encuesta, encontramos que los resultados obtenidos con la aplicación de este instrumento se acercan a los resultados del referendo sobre el TLC. 
Cuadro 8. Porcentaje de las personas que fueron a votar en el referendo del TLC según la opción por la que votó, 2017

\begin{tabular}{lc}
\hline \multicolumn{1}{c}{ Opción por la que votó } & $\begin{array}{c}\text { Porcentaje } \\
(\boldsymbol{n}=\mathbf{6 0 0 )}\end{array}$ \\
\hline Por el Sí & 49,7 \\
Por el no & 42,8 \\
Votó nulo & 3,6 \\
No recuerda & 3,9 \\
Total & $\mathbf{1 0 0}$ \\
\hline
\end{tabular}

IDESPO-UNA. Encuesta A Diez Años del referendo del TLC: Percepciones sobre sus implicaciones sociales, económicas y políticas, 2017.

A quienes indicaron que no fueron a votar se les consultó por las razones por las cuales no asistieron a las urnas. Como muestra el cuadro 7, casi la mitad de las personas que se abstuvieron de votar $(45,75 \%)$ indicó que no lo hizo debido a que no tenían interés en el tema. Esta razón es bastante significativa, ya que evidencia que, a pesar de la campaña realizada por los grupos del "Sí" y del "No"; de la discusión pública llevada a cabo; así como de la relevancia política que el tema adquirió, un grupo significativo de costarricenses no identificó la importancia de la discusión sobre el TLC con los EE. UU., ni sobre el proceso de referendo.

Cuadro 9. Razones por las cuales no se fue a votar en el referendo sobre el TLC, 2017

\begin{tabular}{lc}
\hline \multicolumn{1}{c}{ Razón } & Porcentaje \\
\hline No tenía interés en lo que se estaba discutiendo & 45,7 \\
Quería votar pero no pudo hacerlo & 17,0 \\
Falta de información/conocimiento sobre el tema & 8,9 \\
No podía votar porque no estaba en el país & 8,0 \\
Pensaba que el TLC no tenía relación con su vida & 4,4 \\
No recuerda la razón & 4,0 \\
Confusión, miedo e inseguridad con respecto al & 3,1 \\
tema & 2,3 \\
Pérdida de confianza en la política. & 0,9 \\
No le gusta votar & 5,3 \\
Otro & 100 \\
Total &
\end{tabular}

IDESPO-UNA. Encuesta A Diez Años del referendo del TLC: Percepciones sobre sus implicaciones sociales, económicas y políticas, 2017. 
Sin embargo, es importante señalar que lo expresado por la población encuestada acerca de "la falta de interés", contradice los datos obtenidos en otros estudios de opinión pública realizados durante el periodo de campaña del referendo. Así, Rodríguez, Gómez Barrantes y Chacón (2008) hacen un balance de los resultados de diversas encuestas publicadas en el 2007, en las cuales se le consultó a la población respecto a su posición ante el TLC y en cuanto a la información a la que tenían acceso para aprobar o rechazar el Tratado. Los datos recolectados por estos autores no muestran que haya habido manifestaciones importantes de "falta de interés" en ese momento, sino más bien que la falta de posición respecto al Tratado se debía, en muchos casos, a la dificultad de acceder a información de simple comprensión o que se considerara balanceada y veraz (Rodríguez, Gómez Barrantes y Chacón 2008).

De esta forma, se puede plantear, a manera de hipótesis, que el señalamiento de "falta de interés" para no votar en el referendo sobre el TLC puede deberse a una reconstrucción a posteriori que algunas personas efectuaron. Su propósito era justificar que no tomaron una decisión, en dicho momento, debido a que no comprendieron la información disponible y, a partir de esta, no adoptaron una postura a favor o en contra del Tratado comercial.

Cuadro 10. Calificación otorgada por la población entrevistada a diversas razones según grado de influencia en su decisión de votar en el referendo, 2017

\begin{tabular}{|c|c|}
\hline Razones que influyeron en su voto & $\begin{array}{l}\text { Calificación } \\
\text { promedio* }\end{array}$ \\
\hline La lectura de estudios o análisis sobre el TLC. & 3,6 \\
\hline $\begin{array}{l}\text { Las declaraciones realizadas por personas académicas sobre el } \\
\text { TLC. }\end{array}$ & 3,5 \\
\hline Las conversaciones que tuvo con familiares, amigos o vecinos. & 3,5 \\
\hline Las noticias que informaron sobre el TLC y sus alcances. & 3,3 \\
\hline Las campañas realizadas por los grupos del No y del Sí. & 3,2 \\
\hline Las conversaciones que tuvo con compañeros/as de trabajo. & 3,1 \\
\hline Las declaraciones de empresarios nacionales sobre el TLC. & 3,0 \\
\hline La participación de figuras políticas nacionales en las campañas. & 2,9 \\
\hline $\begin{array}{l}\text { Las acciones y declaraciones realizadas por los Comités } \\
\text { Patrióticos }\end{array}$ & 2,9 \\
\hline $\begin{array}{l}\text { Las manifestaciones realizadas por los superiores de su lugar de } \\
\text { trabajo o de su lugar de estudio en ese momento. }\end{array}$ & 2,6 \\
\hline Las declaraciones de políticos extranjeros sobre el TLC. & 2,4 \\
\hline Las declaraciones de empresarios extranjeros sobre el TLC. & 2,4 \\
\hline
\end{tabular}


Respecto a las personas que indicaron que sí votaron en el referendo, se les consultó qué tanto influyeron diversas razones en la emisión de su voto. Para ello, se les preguntó, sobre una escala de 1 a 5 , donde 1 significaba que la razón no le influyó en nada; y 5 , que influyó completamente (ver cuadro 10). Es necesario hacer la advertencia de que se les consultó a las personas entrevistadas por un proceso que sucedió diez años antes; por lo tanto, sus respuestas pueden estar limitadas a aspectos como su capacidad retentiva o influenciadas por acontecimientos posteriores que pueden modificar su memoria o posición ante el proceso del TLC.

La razón más influyente, a la hora de determinar cómo votar el referendo sobre el TLC, fue "la lectura de estudios o análisis sobre el TLC", seguido por "las declaraciones realizadas por personas académicas sobre el TLC". Si bien estas respuestas apuntan a la importancia de la discusión académica sobre el tema para la población y la reflexión que esta pudo hacer, es necesario matizarla con las dificultades para acceder a información balanceada, o al menos, a los argumentos de los grupos del "Sí" y del "No" en proporción más o menos similar (Cortés Ramos 2008; Rodríguez, Gómez Barrantes, y Chacón 2008). Asimismo, si el electorado tenía la capacidad de procesar la información sobre temas tan diversos y complejos, de manera que pudiera tomar una decisión informada (Willis y Seiz 2012). Por lo tanto, no puede descartarse la tesis de que algún segmento de la población encuestada se está apoyando en estas opciones para legitimar o justificar la manera en que votó, sin que realmente hayan comprendido a profundidad los análisis académicos.

Otras razones que influyeron de manera importante en la forma en que la ciudadanía decidió votar fueron "las conversaciones que tuvo con familiares, amigos y vecinos" $(3,51)$, "las noticias que informaron sobre el TLC y sus alcances" $(3,27)$ y "las campañas realizadas por los grupos del "No" y del "Sí" $(3,22)$. Estas razones apuntan a que hubo una importante necesidad de la población de informarse y de discutir para determinar por cuál opción votarían en el referendo sobre el TLC, especialmente, con su grupo social más cercano.

Un tercer grupo de razones que influyeron en la manera que la población decidió votar fueron "las conversaciones que tuvieron con compañeros/as del trabajo" $(3,07)$ y las "declaraciones de empresarios nacionales" $(3,04)$. Esto refleja la importancia que los temas relacionados al acceso a fuentes de empleo tuvieron durante la campaña.

Para observar de manera más clara cómo las razones consultadas influyeron en la decisión de la población acerca del referendo, se efectuó un análisis de factores, el cual permitió agrupar las razones en cuatro componentes o factores (ver cuadro 11). El factor 1 agrupa la afectación por las declaraciones de figuras políticas y empresarios, tanto nacionales como extranjeros. El factor 2 agrupa las razones vinculadas a conversaciones realizadas por la persona en espacios próximos, como el lugar de trabajo y su familia. El factor 3 agrupa elementos relacionados con la información recibida por los medios y las cam- 
pañas realizadas por los grupos del "Sí" y del "No". El factor 4 agrupa las declaraciones de académicos y la lectura de estudios o análisis sobre el TLC.

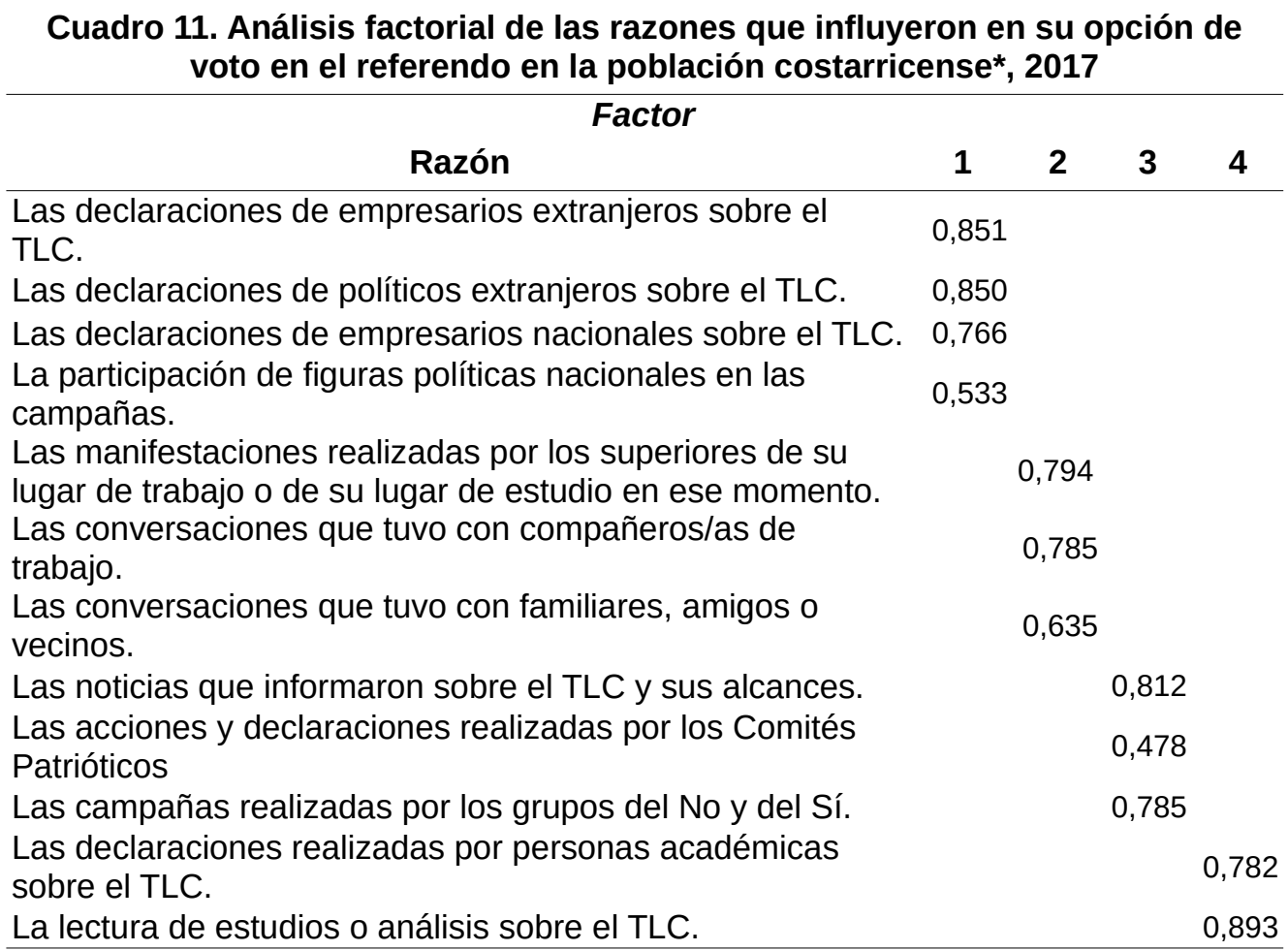

*Explica el $67,66 \%$ de la varianza

Método de extracción: análisis de componentes principales.

Método de rotación: Varimax con normalización Kaiser.

Construcción propia, a partir de IDESPO-UNA. Encuesta A Diez Años del referendo del TLC: Percepciones sobre sus implicaciones sociales, económicas y políticas, 2017.

Posteriormente, se construyó un modelo de regresión logística binaria, con el propósito de observar cómo estos factores, en conjunto con otras variables sociodemográficas, pudieron incidir en la manera de votar en el referendo por parte de la población encuestada (ver cuadro 9). Los datos obtenidos indican que solo tres variables muestran una relación significativa con el modo en que la población emitió su voto. La primera es el factor 1 , es decir, las declaraciones de políticos y empresarios nacionales y extranjeros; de esta manera, las personas que manifestaron estar más influenciadas por este factor tuvieron menor probabilidad de votar por el No, en otras palabras, aumenta la probabilidad de que votaran por el Sí. 
Cuadro 12. Modelo de regresión logística binaria con los factores que afectaron que la población votara Sí o No en el referendo del TLC, 2017

\begin{tabular}{lcc}
\hline \multicolumn{1}{c}{ Variables } & B & Sig. \\
\hline Influencia de figuras públicas (Factor 1) & $-0,429$ & 0,005 \\
Socialización política (Factor 2) & 0,248 & 0,091 \\
Campaña mediática (Factor 3) & $-0,129$ & 0,372 \\
Información académica (Factor 4) & 0,655 & 0,000 \\
Edad & $-0,025$ & 0,019 \\
Constante & 1,108 & 0,044 \\
\hline
\end{tabular}

Sig $>0,05$

*La base del modelo es votar "no".

**El modelo clasifica, de manera correcta, $69,8 \%$ de los casos.

Construcción propia, a partir de IDESPO-UNA. Encuesta A Diez Años del referendo del TLC: Percepciones sobre sus implicaciones sociales, económicas y políticas, 2017.

La segunda variable significativa es el Factor 4, el cual agrupa la influencia por declaraciones de personas académicas y la lectura de textos analíticos sobre el TLC. En este caso, quienes manifestaron estar más influenciadas por estos elementos tienen mayor probabilidad de haber votado por el No. La última variable que se relaciona de manera significativa es la edad de las personas encuestadas. Para este caso, a mayor edad de la persona encuestada, menos probable es que votaran por el No.

Respecto de la opinión de la población en torno al uso del referendo como herramienta para la toma de decisiones (ver cuadro 13), más de $70 \%$ de las personas encuestadas coincidió en que estos son mecanismos adecuados para tomar decisiones sobre asuntos controversiales. En este sentido, la opinión favorable de la población demuestra que el referendo cuenta con respaldo y legitimidad social, aun cuando es una figura relativamente nueva en el panorama democrático nacional. Es necesario indicar que la literatura académica ha señalado que los referendos son mecanismos útiles para dirimir conflictos sociales y políticos, siempre y cuando respondan a una iniciativa ciudadana; asimismo, son útiles para "desbloquear" problemas de toma de decisiones en instancias políticas, sobre temas controversiales. Sin embargo, en el caso de los referendos que son iniciativa de un poder de la República, su propósito central es legitimar la posición de un grupo en el poder, respecto a una política o acción que no está siendo bien acogida en otra instancia de Gobierno (por ejemplo, el Congreso); por lo tanto, pierden su efectividad como mecanismos de solución de conflictos sociopolíticos y, al contrario, pueden provocar problemas de deslegitimación del sistema político (Altman 2011).

Un 50,8\% de la población señaló estar en desacuerdo con el enunciado de que los partidos políticos deben ser los únicos autorizados para hacer campaña durante los procesos de referendo. Este porcentaje se complementa con 33,8\% que respondió estar totalmente en desacuerdo con esta posibilidad. Relacionado con lo anterior, se consultó si debería garantizarse que las 
diferentes tendencias o grupos que participan en la campaña de un referendo tengan acceso equitativo a un financiamiento público: a lo que un 71,3\% respondió de manera positiva. En contraposición, apenas un 18,2\% y un 7,0\% de las personas aseguró estar en desacuerdo y totalmente en desacuerdo con la frase mencionada. Como se indicó, durante la campaña del referendo, se plantearon serias críticas alrededor del tema de la inequidad del financiamiento entre los grupos del "Sí" y del "No"; incluso, algunas personas del grupo del "Sí" hicieron eco a estas críticas (Gutiérrez 2012). Por lo tanto, no es de extrañar que un grupo mayoritario de la población encuestada dijera estar anuente con el establecimiento de un financiamiento equitativo entre las partes involucradas.
Cuadro 13. Porcentaje de personas entrevistadas según qué tan de acuerdo o en desacuerdo se encuentra con frases relacionadas con la realización de referendos como instrumentos de toma de decisiones, 2017

\begin{tabular}{lccc}
\hline & $\begin{array}{c}\text { De acuerdo o } \\
\text { totalmente de } \\
\text { acuerdo }\end{array}$ & $\begin{array}{c}\text { Ni de acuerdo ni } \\
\text { en desacuerdo }\end{array}$ & $\begin{array}{c}\text { En desacuerdo o } \\
\text { totalmente en } \\
\text { desacuerdo }\end{array}$ \\
\hline $\begin{array}{l}\text { Los referendos son mecanismos } \\
\text { adecuados para tomar } \\
\text { decisiones sobre asuntos } \\
\text { controversiales para la población } \\
\text { costarricense. }\end{array}$ & 74,9 & 6,0 & 17,1 \\
$\begin{array}{l}\text { Los partidos políticos deben ser } \\
\text { los únicos a los que se les debe } \\
\text { permitir hacer campaña en los } \\
\text { procesos de referendo. }\end{array}$ & 13,7 & 1,7 & \\
$\begin{array}{l}\text { Se debe garantizar un } \\
\text { financiamiento público equitativo }\end{array}$ & & & \\
$\begin{array}{l}\text { a las diferentes tendencias o } \\
\text { grupos que participan en la } \\
\text { campaña del referendo. }\end{array}$ & 71,3 & & \\
$\begin{array}{l}\text { Se debe permitir que las altas } \\
\text { autoridades políticas del país } \\
\text { (presidente de la República, } \\
\text { diputados/as, ministros/as, etc.) } \\
\text { hagan campaña durante los } \\
\text { referendos. }\end{array}$ & & 3,5 & \\
$\begin{array}{l}\text { Se debe permitir que actores } \\
\text { privados, como empresas o } \\
\text { medios de comunicación, hagan } \\
\text { campaña durante los referendos. }\end{array}$ & 38,2 & & \\
\hline
\end{tabular}

IDESPO-UNA. Encuesta A Diez años del referendo del TLC: Percepciones sobre sus implicaciones sociales, económicas y políticas, 2017.

Adicionalmente, se preguntó si se debía permitir que las altas autoridades del país — como el presidente de la República, diputados/as, ministros/as y otras figuras políticas- se involucren activamente en la campaña durante este tipo de procesos consultivos. Los resultados obtenidos muestran que más de $75 \%$ de las personas encuestadas señaló no estar de acuerdo con la partici- 
pación del grupo de representantes del Gobierno en los procesos de campaña de un referendo, mientras que 19\% afirmó lo contrario.

Finalmente, 54,7\% de la población indicó estar en desacuerdo o muy en desacuerdo con la posibilidad de que actores privados intervengan en la campaña de un referendo. No obstante, un porcentaje también considerable $(38,2 \%)$ está de acuerdo con que empresas privadas o medios de comunicación dirijan sus recursos y participen en las actividades que se desarrollan durante el periodo de campaña.

\section{Percepción sobre los beneficios y perjuicios del TLC}

A la población encuestada se le consultó si la implementación del Tratado de Libre Comercio (TLC) había generado beneficios y para quién. La pregunta fue "En una escala del 1 al 10, donde 1 es la nota más baja y 10 la más alta, en Costa Rica ¿cuánto se han beneficiado los siguientes grupos con el TLC?" Entre los grupos identificados como los más beneficiados se encontraron los grandes grupos empresariales, tanto extranjeros como nacionales, seguidos por el Gobierno. ${ }^{2}$ Para el resto de grupos, las calificaciones descienden a menos de la mitad del valor de la escala: las personas consumidoras; los pequeños y medianos empresarios nacionales; la población costarricense; las personas trabajadoras costarricenses; y los pequeños y medianos agricultores nacionales.

Cuadro 14. Percepción sobre el beneficio obtenido por distintos grupos debido a la aprobación del TLC en Costa Rica, 2017

\begin{tabular}{lc}
\hline \multicolumn{1}{c}{ Grupo beneficiado } & Calificación promedio* $^{*}$ \\
\hline Grandes empresarios nacionales. & 8,3 \\
El Gobierno. & 7,2 \\
Las personas consumidoras & 4,9 \\
Los pequeños y medianos empresarios nacionales. & 4,8 \\
La población costarricense & 4,6 \\
Las personas trabajadoras costarricenses & 4,5 \\
Pequeños y medianos agricultores nacionales. & 3,9 \\
\hline
\end{tabular}

*Se le consultó a la población encuestada: En una escala del 1 al 10, donde 1 es la nota más baja y 10 la más alta ¿Cuánto se han beneficiado los siguientes grupos por la aprobación del TLC?

IDESPO-UNA. Encuesta A Diez años del referendo del TLC: Percepciones sobre sus implicaciones sociales, económicas y políticas", 2017.

También se les consultó a las personas entrevistadas sobre cuál había sido la utilidad del TLC, a partir de la siguiente pregunta: "Le voy a leer una serie de opciones, ¿podría decirme si usted piensa que el TLC ha servido mucho, algo, poco o nada?".
2. Durante el proceso del TLC el Gobierno hace referencia a la segunda administración Arias Sánchez (2006-2010) 
En la tabla 1, se muestra la calificación otorgada de acuerdo con la escala empleada y valores promedio. En esta pregunta, se empleó una escala de 1 a 4, donde 1 significa mucho; 2, algo; 3, poco; y 4, nada.

Para el caso de la categoría "mucho", se observa que no se contemplan valores dentro de este rango. La categoría "algo" fue la que obtuvo mayor número de respuestas, en la que se registran estas premisas positivas: mejorar las condiciones para sector servicios $(1,7)$; brindar un mayor acceso a los servicios $(1,8)$; tener acceso a una mayor cantidad de productos $(1,9)$; mejorar la calidad de los servicios (1,9); aumentar la influencia de Estados Unidos $(2,0)$; tener acceso a productos de mayor calidad $(2,0)$; atraer la inversión de empresas $(2,10)$; aumentar las exportaciones $(2,1)$; promover el crecimiento $(2,3)$; promover la integración económica $(2,4)$; así como las siguientes premisas negativas: empeorar las condiciones de productos naturales los productores nacionales $(1,9)$; perder empleos $(2,0)$; que Costa Rica pierda independencia $(2,4)$.

Tabla 1. Para qué ha servido el TLC, 2017

\begin{tabular}{lc}
\hline \multicolumn{1}{c}{ Beneficio del TLC } & $\begin{array}{c}\text { Respuesta } \\
\text { promedio }\end{array}$ \\
\hline Mejorar las condiciones para sector servicios & \\
Brindar un mayor acceso a los servicios & \\
Tener acceso a una mayor cantidad de productos & \\
Empeorar las condiciones de productos naturales & \\
Mejorar la calidad de los servicios & \\
$\begin{array}{l}\text { Aumentar la influencia de Estados Unidos } \\
\text { Perder empleos }\end{array}$ & Algo \\
Tener acceso a productos de mayor calidad & \\
Atraer la inversión de empresas & \\
Aumentar las exportaciones & \\
Promover el crecimiento & \\
Que Costa Rica pierda independencia & \\
Promover la integración económica & Poco \\
\hline Mismorar los precios de los productos & Poinuir la pobreza en Costa Rica \\
\hline
\end{tabular}

IDESPO-UNA. Encuesta A Diez años del referendo del TLC: Percepciones sobre sus implicaciones sociales, económicas y políticas", 2017.

Para la categoría "poco", se observa que la calificación brindada incluye únicamente dos premisas: mejorar los precios de los productos $(2,6)$ y disminuir la pobreza en Costa Rica $(3,1)$. Finalmente, al igual que la categoría de "mucho", para el caso de "nada"; el promedio de respuestas no incluye premisas para esta categoría, lo que evidencia que las respuestas fueron agrupadas en el nivel central de la escala.

Adicionalmente, se preguntó: "si el día de hoy se llevara a cabo una consulta ciudadana para decidir si Costa Rica debe o no seguir en el TLC, ¿usted cómo votaría?". El 44,1\% de la población encuestada manifestó que votaría 
por mantener el Tratado; mientras que 44,4\%, votaría por salirse del TLC, lo que evidencia que, aún diez años después, la polarización respecto al "Sí" y al "No" continúa.

Cuadro 15. Porcentaje de la población según cómo votaría para mantenerse o salirse del TLC, 2017

\begin{tabular}{lc}
\hline \multicolumn{1}{c}{ Posición } & Porcentaje \\
\hline A favor de mantenerse en el TLC & 44,1 \\
A favor de salirse del TLC & 44,5 \\
Le es indiferente & 11,5 \\
Total & $\mathbf{1 0 0}$ \\
\hline
\end{tabular}

IDESPO-UNA. Encuesta "A Diez años del referendo del TLC: Percepciones sobre sus implicaciones sociales, económicas y políticas”, 2017.

El grupo de la población de mayor tamaño que cambiaría de opinión, respecto a la forma que emitió su voto en el 2007, proviene de quienes votaron "Sí al TLC". De esta manera, más de $26 \%$ de las personas que votaron a favor del TLC en el 2007, votarían ahora por salirse del Tratado. En cuanto a los que votaron por el "No al TLC" en el 2007, el 16\% votaría por mantener al país dentro del Tratado (ver Diagrama 1).

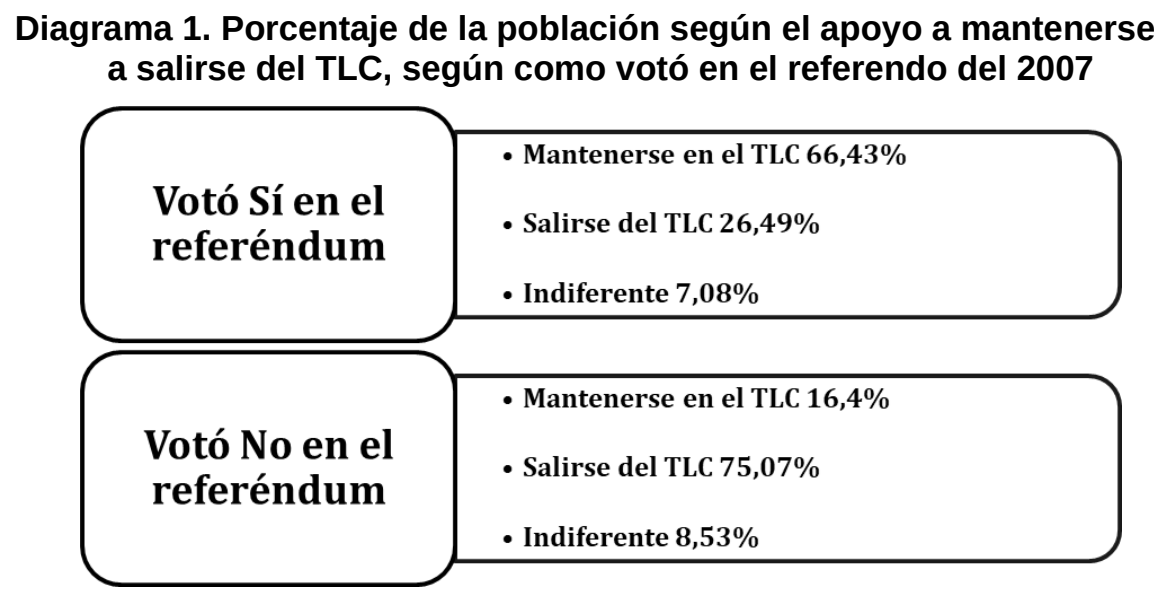

IDESPO-UNA. Encuesta "A Diez años del referendo del TLC: Percepciones sobre sus implicaciones sociales, económicas y políticas”, 2017.

\section{Percepción sobre la campaña del TLC y otros referendos}

En el caso de la campaña realizada en el marco del referendo por el TLC, a la población encuestada se le presentaron una serie de frases, con el objeti- 
vo de observar el grado de acuerdo o de desacuerdo. Como se observa en el cuadro 16, un porcentaje mayoritario de la población encuestada estuvo algo en desacuerdo o muy en desacuerdo con la frase que señala que "el acceso a los recursos económicos para hacer campaña fue equitativo entre las tendencias del Sí y el No". De esta manera, 58,7\% indicó estar algo en desacuerdo o muy en desacuerdo, frente a $34,7 \%$ que señaló que los recursos económicos fueron equitativos entre las tendencias del "Sí" y del "No".

Cuadro 16. Porcentaje de personas entrevistadas, según qué tan de acuerdo o en desacuerdo se encuentra con frases relacionadas a la campaña realizada durante el referendo sobre el TLC, 2017

\begin{tabular}{|c|c|c|c|c|c|}
\hline Frases & $\begin{array}{l}\text { Muy de } \\
\text { acuerdo }\end{array}$ & $\begin{array}{l}\text { Algo de } \\
\text { acuerdo }\end{array}$ & $\begin{array}{c}\text { Ni de } \\
\text { acuerdo ni } \\
\text { en } \\
\text { desacuerdo }\end{array}$ & $\begin{array}{c}\text { Algo en } \\
\text { desacuerdo }\end{array}$ & $\begin{array}{c}\text { Muy en } \\
\text { desacuerdo }\end{array}$ \\
\hline $\begin{array}{l}\text { El acceso a los recursos } \\
\text { económicos para hacer } \\
\text { campaña fue equitativo entre } \\
\text { las tendencias del Sí v el No. }\end{array}$ & 11,2 & 23,5 & 6,7 & 28,4 & 30,3 \\
\hline $\begin{array}{l}\text { El resultado del referendo se } \\
\text { vio afectado por actores } \\
\text { privados, como empresas o } \\
\text { medios de comunicación. }\end{array}$ & 36,7 & 31,6 & 5,4 & 14,7 & 11,7 \\
\hline $\begin{array}{l}\text { La actuación del Tribunal } \\
\text { Supremo de Elecciones fue } \\
\text { adecuada para resolver los } \\
\text { problemas y conflictos } \\
\text { surgidos durante la campaña } \\
\text { del referendo. }\end{array}$ & 31,7 & 32,3 & 8,0 & 12,0 & 15,9 \\
\hline $\begin{array}{l}\text { Los medios de comunicación } \\
\text { fueron "neutrales" al } \\
\text { presentar la información } \\
\text { sobre las tendencias del Sí y } \\
\text { del No. }\end{array}$ & 22,3 & 21,3 & 6,0 & 21,9 & 28,5 \\
\hline $\begin{array}{l}\text { La sociedad civil tuvo } \\
\text { espacios adecuados para } \\
\text { participar. }\end{array}$ & 29,4 & 33,1 & 5,8 & 17,1 & 14,6 \\
\hline $\begin{array}{l}\text { En general, el proceso de } \\
\text { referendo por el TLC fue } \\
\text { justo. }\end{array}$ & 23,4 & 30,6 & 7,4 & 16,8 & 21,8 \\
\hline $\begin{array}{l}\text { Hubo fraude electoral que } \\
\text { afectara el resultado del } \\
\text { referendo. }\end{array}$ & 6,8 & 10,9 & 10,4 & 25,7 & 46,2 \\
\hline
\end{tabular}

IDESPO-UNA. Encuesta A Diez Años del referendo del TLC: Percepciones sobre sus implicaciones sociales, económicas y políticas, 2017.

En cuanto a la frase "el resultado del referendo se vio afectado por actores privados, como empresas o medios de comunicación", 68,3\% de la población indicó estar muy de acuerdo o algo de acuerdo, mientras que $26,4 \%$ señaló estar en desacuerdo o muy en desacuerdo. De la misma manera, ante la premisa "los medios de comunicación fueron "neutrales" al presentar la informa- 
ción sobre las tendencias del "Sí" y el "No", 43,6\% de la población encuestada señaló su desacuerdo al respecto, mientras que 50,4\% estuvo algo de acuerdo o muy en desacuerdo.

La participación del Tribunal Supremo de Elecciones (TSE) fue bien valorada por la población encuestada, dado que ante la frase "la actuación del Tribunal Supremo de Elecciones fue adecuada para resolver los problemas y conflictos surgidos durante la campaña del referendo", 64,1\% de la población estuvo de acuerdo o muy de acuerdo. El porcentaje de la población que se manifestó en desacuerdo con esta frase $(27,9 \%)$ fue minoritario, aunque no por ello poco significativo. En cuanto a la proposición "la sociedad civil tuvo espacios adecuados para participar", $62,5 \%$ de las personas consultadas indicaron estar algo o muy de acuerdo con la frase expuesta; frente a 31,7\% que afirmó lo contrario.

Respecto a las consideraciones del referendo como un proceso justo, 54\% de la población encuestada señaló que el proceso lo fue, mientras que 38,6\% indicó lo contrario. Ante la frase "hubo fraude electoral que afectara el resultado del referendo", 17,7\% indicó estar algo o muy de acuerdo, es decir, afirmó la tesis de que sí hubo fraude en el proceso de referendo por el TLC, a pesar de que la mayoría de la población encuestada $(71,9 \%)$ indicó estar algo o muy en desacuerdo.

En el contexto de ejecución del referendo, las posiciones enfrentadas en torno al rechazo o a la aprobación del Tratado diseñaron distintas estrategias para plantear su posicionamiento y conseguir votos. De esta forma, el "Sí" al TLC recurrió al miedo como estrategia política para desalentar a quienes iban a darle su apoyo al "No". Para ello, Kevin Casas — vicepresidente de la República de la Administración Arias Sánchez (2006-2010) - y Fernando Sánchez — diputado liberacionista - escribieron lo que se conoce como el "Memorándum del miedo". Este documento, que fue publicado en el Semanario Universidad, promovía el miedo al señalar que, ante un triunfo del "No", el país se vería sometido a la pérdida de empleos, al debilitamiento de las instituciones democráticas, al aumento de ingobernabilidad y a la injerencia de gobiernos y figuras de la izquierda latinoamericana, como los de Fidel Castro, Hugo Chávez o Daniel Ortega. Para conocer la posición de la población encuestada sobre este instrumento, se planteó la pregunta: “¿usted recuerda el memorándum elaborado por Kevin Casas (exvicepresidente) y Fernando Sánchez (exdiputado)?".

Como se observa, la mayor parte de la población (81\%) indicó no recordar el Memorándum del miedo, frente a $17 \%$ que sí lo recordó, lo que corresponde a 102 personas de la muestra (ver gráfico 1). Por su parte, entre los aspectos recordados del memorándum, destacan su objetivo: infundir miedo, así como que fue una estrategia ejecutada por la posición favorable al Tratado (ver cuadro 17). 
Gráfico 1. Porcentaje de personas que recuerdan el memorándum elaborado por Kevin Casas y Fernando Sánchez, 2017

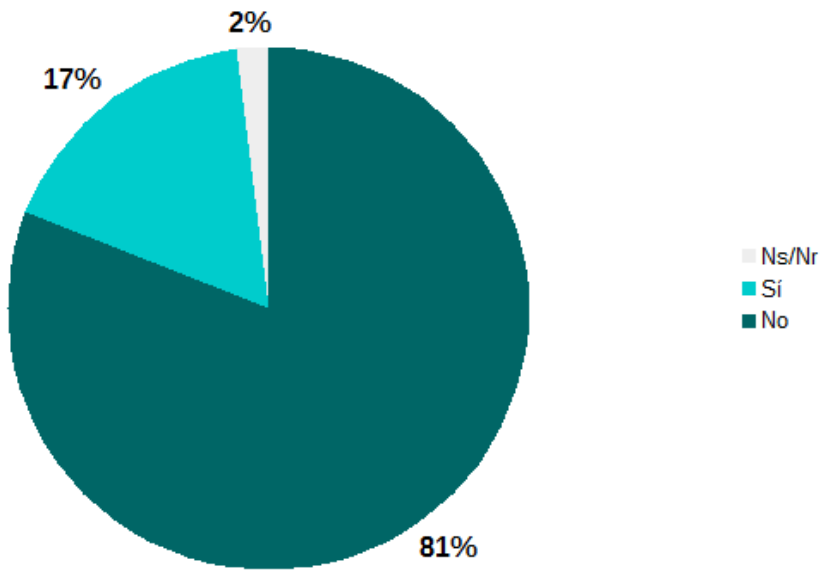

IDESPO-UNA. Encuesta A Diez Años del referendo del TLC: Percepciones sobre sus implicaciones sociales, económicas y políticas, 2017.

Cuadro 17. Aspectos del memorándum que la población encuestada recuerda más (distribución porcentual)

\begin{tabular}{lc}
\hline & $\begin{array}{c}\text { Porcentaje } \\
\text { (n= 600) }\end{array}$ \\
\hline Tenía como objetivo infundir miedo & 43,0 \\
Fue una estrategia del Sí & 18,0 \\
Ocultamiento de información & 10,0 \\
El proceso: actores, discursos, impacto mediático, con- & 29,0 \\
secuencias & $\mathbf{1 0 0 , 0}$ \\
Total & \\
\hline
\end{tabular}

IDESPO-UNA. Encuesta A Diez Años del Referéndum del TLC: Percepciones sobre sus implicaciones sociales, económicas y políticas, mayo 2017.

De estas 102 personas, casi 58\% indicó que el documento influyó en la posición de los costarricenses sobre el TLC y solo 22,5\% apuntó a que el memorándum incidió en su propia posición. Por otra parte, más de $65 \%$ de este grupo recordó las frases: "con el TLC, los que hoy vienen en bicicleta, vendrán en motocicleta BMW" y "los que vienen en un Hyundai, vendrán en un Mercedes-Benz". De estos, solo 7,7\% consideró que estas frases cumplieron con sus promesas. Sobre las promesas generales del TLC, únicamente $15,7 \%$ respondió que se cumplieron. Las siguientes son razones que dieron para el cumplimiento o incumplimiento: 
Tabla 2. Razones de cumplimiento o incumplimiento de las promesas del TLC, 2017

\begin{tabular}{|c|c|}
\hline Sí se cumplieron & $\begin{array}{l}\text { No se cumplieron } \\
\end{array}$ \\
\hline $\begin{array}{l}\text { Porque se ha mejorado la inversión y el } \\
\text { funcionamiento del libre mercado. } \\
\text { Porque se ha podido ampliar relaciones } \\
\text { comerciales con otros países, como } \\
\text { China. } \\
\text { Porque han mejorado los precios de los } \\
\text { productos. } \\
\text { Porque se implementaron cambios en } \\
\text { telecomunicaciones. }\end{array}$ & $\begin{array}{l}\text { Porque todo era mentira, se buscaba } \\
\text { engañar al "pueblo". } \\
\text { Porque prometieron mejoras que no } \\
\text { ocurrieron. } \\
\text { Porque prometieron mejoras y la } \\
\text { situación del país empeoró. } \\
\text { Porque la economía no creció. } \\
\text { Porque los empleos no aumentaron. } \\
\text { Porque muchas empresas se fueron del } \\
\text { país. } \\
\text { Porque era un tratado comercial que no } \\
\text { le interesaba mejorar la vida de las y los } \\
\text { costarricenses. }\end{array}$ \\
\hline
\end{tabular}

IDESPO-UNA. Encuesta A Diez Años del referendo del TLC: Percepciones sobre sus implicaciones sociales, económicas y políticas, 2017.

Por otra parte, al observar el bajo porcentaje de personas que recordaban el memorándum, se midió la relación con el papel de los medios de comunicación; para ello, se cruzó la pregunta respecto del grado de influencia de las noticias que informaron sobre el TLC y sus alcances con la pregunta de si la persona encuestada recordaba el Memorándum del miedo. La prueba estadística para medir la asociación entre ambas arrojó que estas sí están relacionadas (Chi cuadrado $p<0,05$ ), aunque de manera débil.

\section{Gráfico 2. Relación entre la influencia de las noticias sobre el TLC y el recuerdo del memorándum, 2017}

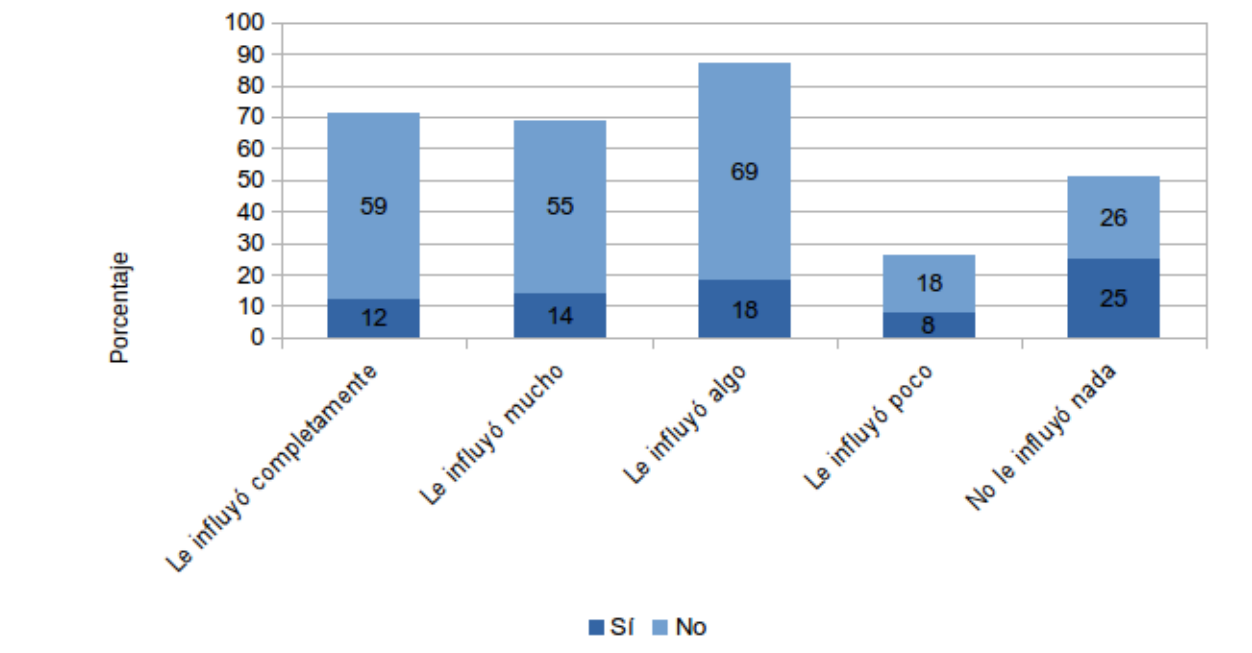

IDESPO-UNA. Encuesta A Diez Años del referendo del TLC: Percepciones sobre sus implicaciones sociales, económicas y políticas, 2017. 
Como se observa en el gráfico 2, la mayoría de personas que contestaron que no recuerdan el memorándum se vieron influidas en algún grado por las noticias en su posición con respecto al TLC; aunque las personas que fueron influidas poco o nada por las noticias, tampoco recuerdan en su mayoría el memorándum. Lo cierto es que este peso es mucho mayor entre quienes sí se vieron influenciados por las noticias. Estos datos muestran el papel que tienen los medios de comunicación con respecto a las coberturas de temas relevantes, así como en influenciar la opinión de la población en cuanto a un tema de interés nacional como lo fue este acuerdo comercial.

\section{Consideraciones finales}

Como se señaló al principio de este artículo, el referendo por el TLC es, posiblemente, una de las coyunturas políticas y sociales más conflictivas en la historia política reciente de Costa Rica, por ello, nos hemos concentrado en analizar cómo la población percibe su impacto tras diez años de ocurrencia de dicho evento. En cuanto al referendo como mecanismo para dirimir procesos controversiales de toma de decisiones, la población encuestada considera que es uno adecuado para solucionar conflictos políticos; asimismo, manifiesta estar complacida por el proceso y la campaña durante el referendo del TLC. Sin embargo, esto no significa que no exprese críticas hacia este proceso e, incluso, la población encuestada considera que deben hacerse modificaciones importantes a dichas campañas; entre las que más destacan: el financiamiento público y la prohibición a las autoridades de Gobierno en participar en estas campañas.

Respecto de los factores que influyeron en la población encuestada a la hora de decidir cómo votar en el referendo, los datos muestran que los documentos analíticos y los aportes de personas académicas fueron los elementos que se perciben más influyeron en la definición del voto, especialmente, entre el grupo que votó por el No al TLC. Si bien es cierto que no es posible corroborar si las personas estudiaron (y comprendieron) con detenimiento los documentos analíticos que circularon durante la campaña del referendo, así como quiénes fueron las personas académicas que influyeron en su voto; durante la campaña del TLC, hubo un alto grado de discusión y de debates sobre el tema. Asimismo, hubo una destacable participación de universidades públicas en este proceso; por lo tanto, no es de extrañar que estos elementos fueran identificados como los más influyentes por la población encuestada.

El hallazgo anterior es relevante, ya que parece contradecir lo establecido por otros estudios acerca de que no hubo suficiente discusión pública en torno al tema y que se impuso la campaña mediática sobre el análisis de los efectos y alcances del TLC, como principal influencia para la toma de decisiones por parte de la ciudadanía (Rojas Bolaños, 2009). Además, los datos re- 
colectados muestran que, para las personas entrevistadas, las acciones realizadas por los grupos ciudadanos, sobre todo, los llamados Comités Patrióticos, no tuvieron un impacto significativo en su decisión de cómo votar, a pesar de existir una amplia literatura académica que analiza el impacto de estos grupos en el referendo sobre el TLC (Álvarez Rudín 2011; Cupples y Larios 2010; Finley-Brook y Hoyt 2009; Frajman 2012).

Ahora bien, los aspectos recién descritos deben ser matizados a partir de dos elementos: el primero, que la encuesta aplicada se realizó el año pasado, diez años después de aprobado el TLC, precisamente para observar las percepciones y las valoraciones tras una década. Esto presenta la limitación de que las respuestas están sujetas a la memoria de las personas encuestadas; por lo tanto, estas no necesariamente reflejan, de manera exacta, las opiniones y percepciones que este grupo tenía en el momento del referendo sobre el TLC. En segundo lugar, otras investigaciones han mostrado que la población costarricense tiende a visualizar la política como una actividad individual, por lo que tienden a considerar que sus decisiones y opiniones provienen de su propia reflexión; así, minimizan el papel que tienen los "otros" en la formación de sus creencias políticas (Díaz González et al., 2018). Por lo tanto, es posible que, tras diez años de transcurrido el referendo sobre el TLC, nos encontremos ante un fenómeno de disonancia cognitiva por parte de la población, la cual minimiza el efecto que los grupos ciudadanos y las campañas mediáticas tuvieron a la hora de definir su voto y, en contraste, sobrevaloran el efecto que la información académica y el criterio técnico tuvo sobre su decisión, para así ser consecuente con la idea de que sus decisiones políticas son fruto de una reflexión individual.

Respecto a quién se ha beneficiado con la aprobación del TLC, la población encuestada identifica que el beneficio ha sido, principalmente, para grandes empresarios nacionales y extranjeros; y más bien, observa que ha sido contraproducente para pequeños y medianos empresarios, productores agrícolas y consumidores. Dado esto, no es extraño observar que diez años después de su aprobación, el TLC continúa polarizando a la población costarricense, así $44,1 \%$ de la población encuestada estaría a favor de mantenerse en el Tratado y $44,5 \%$ apoyaría dejarlo. Asimismo, tras una década, también ha variado la opinión sobre este tratado comercial. Las variaciones más importantes están dentro del grupo que votó por el "Sí" en el 2007, ya que 26,5\% manifestó que estaría dispuesto a salirse del TLC en el 2017.

Por último, es poca la población encuestada que recuerda las controversias surgidas durante la campaña del referendo sobre el TLC, especialmente, en cuanto al Memorándum del miedo. A pesar de ello, las personas que sí lo recuerdan tienden a considerar que afectó la intención de voto de las personas durante este proceso. 


\section{Bibliografía}

Alfaro Redondo, Ronald. 2006. «Elecciones nacionales 2006 en Costa Rica y la recomposición del sistema de partidos políticos». Revista de Ciencia Política 26(1): 125-37.

Alfaro Redondo, Ronald. 2009. «Elecciones a mitad de la primera década del siglo XXI en Costa Rica». En Elecciones 2006 y Referéndum: perspectivas diversas, editado por Manuel Rojas Bolaños y Mariela Castro Ávila. San José: FLACSO.

Alfaro Salas, Sergio, y José Andrés Díaz González. 2008. «El primer referéndum en la democracia más antigua de Latinoamérica: análisis crítico y lecciones aprendidas en el Referéndum 2007». En IV Congreso ALACIP: ¿Gobernanza sin desarrollo? Repensar el bienestar de América Latina. Universidad de Costa Rica.

Almeida, Paul. 2016. Neoliberalismo y movimientos populares en Centroamérica. El Salvador: UCA Editores.

Altman, David. 2011. Direct Democracy. New York: Cambridge University Press.

Álvarez Rudín, y Mercedes Álvarez. 2011. «Movimientos sociales y participación política: El movimiento contra el TLC en la campañana del referéndum 2007 en Costa Rica». Anuario de Estudios Centroamericanos 37: 201-30.

Behlman, Jordan. 2014. «Out on a Rim: Pacific Rim's Venture Into CAFTA's Denial of Benefits Clause». The University of Miami Inter-American Law Review 45(2): 397-424.

Cortés Ramos, Alberto. 2008. «Los límites del referendo sobre el TLC como instrumento de participación política en Costa Rica». Revista de Ciencias Sociales 121: 31-47.

Cupples, Julie, y Irving Larios. 2010. «A Functional Anarchy: Love, Patriotism, and Resistance to Free Trade in Costa Rica». Latin American Perspectives 37(6): 93-108. https://doi.org/10.2307/25750422.

Díaz González, José Andrés, Sindy Mora Solano, Luis Diego Soto Kiwit, Martín Solís Salazar, Anamaría Hernández Barrantes, y Norman Solórzano Alfaro. 2018. Imaginarios políticos. Des-pensando y repensando la convivencia democrática desde la perspectiva ciudadana. Heredia: EUNA. 2018.

Finley-Brook, Mary, y Katherine Hoyt. 2009.«CAFTA Opposition: Divergent Networks, Uneasy Solidarities». Latin American Perspectives 36(6): 2745. 
Frajman, Eduardo. 2012. «The People, Not the Movement: Opposition to CAFTA in Costa Rica, 2002-2007». Latin American Perspectives 39(6): 116-32.

IDESPO-UNA. 2007. «Encuesta: percepción de la población costarricense sobre la Asamblea Legislativa y el Gobierno». Universidad Nacional de Costa

Rica. http://www.repositorio.una.ac.cr/bitstream/handle/11056/7320/ops51.pdf ?sequence $=1 \&$ isAllowed $=y$.

Mora Solano, Sindy. 2009. «Elecciones, Sociedad Civil, Acciones Colectivas y Movimientos Sociales». En Elecciones 2006 y referéndum: perspectivas diversas, editado por Manuel Rojas Bolaños y Mariela Castro Ávila, 93-144. FLACSO-Costa Rica.

Mora Solano, Sindy. 2016. La política de la calle: organización y autonomía en la Costa Rica contemporánea.. San José: EUCR. 2016.

Pignataro, Adrián. 2016. Manual para el Análisis Político Cuantitativo. Primera Edición. San José: EUCR. 2016.

Pinder, Sherrow O. 2009. «The Dominican Republic and Central America Free Trade Agreement with the USA: Some Concerns». Development in Practice 19(2): 227-32.

Raventós Vorst, Ciska. 2008. «Balance del referendo sobre el TLC en Costa Rica a la luz de la teoría de la democracia». Revista de Ciencias Sociales 121: 13-29.

Raventós Vorst, Ciska, Marco Vinicio Fournier Facio, Diego Fernández Montero, y Ronald Alfaro Redondo. 2014. Respuestas ciudadanas ante el malestar con la política: Salida, voz y lealtad. San José: EUCR.

Rayner, Jeremy. 2014. «When Participation Begins with a 'NO': How Some Costa Ricans Realized Direct Democracy by Contesting Free Trade». Etnofoor 26(2): 11-32.

Rodríguez, Florisabel, Miguel Gómez Barrantes, y Wendy Chacón. 2008. «El referéndum del TLC en Costa Rica: seguimiento de la opinión pública». Revista de Ciencias Sociales 121: 49-69.

Rojas Bolaños, Manuel. 2009. «Elecciones y Referéndum: Un balance general». En Elecciones 2006 y referéndum: perspectivas diversas, editado por Manuel Rojas Bolaños y Mariela Castro Ávila, 11-56. FLACSO-Costa Rica.

Spalding, Rose J. 2007. «Civil Society Engagement in Trade Negotiations: CAFTA Opposition Movements in El Salvador». Latin American Politics and Society 49(4): 85-114.

Taylor, J. Edward, Antonio Yúnez Naude, y Nancy Jesurun-Clements. 2010. «Does Agricultural Trade Liberalization Reduce Rural Welfare in Less Developed Countries? The Case of CAFTA». Applied Economic Perspectives and Policy 32(1): 95-116. 
Urbatsch, Robert. 2013. «A Referendum on Trade Theory: Voting on Free Trade in Costa Rica». International Organization 67(1): 197-214.

Willis, Eliza J. y Janet A. Seiz. 2012. «The CAFTA Conflict and Costa Rica's Democracy: Assessing the 2007 Referendum». Latin American Politics and Society 54(3): 123-56. https://doi.org/10.2307/23321721. 